\title{
Alternativo
}

\section{IMPLICAÇÕES DOS PRINCÍPIOS DA PREVENÇÃO E DA PRECAUÇÃO NA SAÚDE AMBIENTAL}

\author{
Hidemburgo Gonçalves Rocha (1) \\ Lindeberg Rocha Freitas (2)
}

\begin{abstract}
Resumo
O presente estudo pretende destacar e exemplificar a correlação entre meio ambiente e saúde, inclusive sob o aspecto legal, e mostrar a importância da aplicação dos princípios da prevenção e da precaução, referentes ao Direito Ambiental Brasileiro.
\end{abstract}

Palavras-Chave: Saúde, Meio ambiente, Direito ambiental

\section{Introdução}

Os recursos naturais, sua organização e perspectiva de continuidade e desenvolvimento tem sido objeto de diversos estudos no meio acadêmico (HOGAN, 2002).

Exigências cada vez mais complexas da sociedade moderna vêm acelerando o uso dos recursos naturais, resultando em danos ambientais que colocam em risco a sobrevivência da humanidade no planeta (SOUZA, 2004).

Por toda a nossa história há indícios de utilização dos recursos naturais de maneira indiscriminada. Seja para o desenvolvimento da tecnologia ou da economia, de forma a garantir uma vida com mais qualidade. Entretanto, não podemos assegurar que a exploração dos recursos naturais traga desenvolvimento e qualidade de vida, necessariamente. Isso porque os recursos oriundos da natureza não estão sendo aproveitados de forma regulada, causando sérios danos ao meio ambiente e refletindo negativamente na própria condição de vida e de saúde do homem. 
Moraes (2004), expõe que "tudo se tornou válido em nome do progresso, do bem estar da sociedade e da vida mais confortável" (MORAES, 2004). Na realidade, esta busca do homem por uma vida melhor está lhe trazendo doenças, problemas sociais e comprometendo seu futuro na Terra, já que suas ações não tem respeitado as condições mínimas para a manutenção dos nossos recursos naturais. Dessa forma, o meio ambiente tende a comprometer a saúde.

\section{O ambiente e a saúde}

Diversos são os conceitos atribuídos a "meio ambiente". A Fundação Estadual de Engenharia do Meio Ambiente (1990) o define como um sistema no qual interagem fatores de ordem física, biológica e sócio-econômica. Já Silva (2002) acredita que meio é a interação do conjunto de elementos naturais, artificiais e culturais que propiciam o desenvolvimento equilibrado da vida em todas suas formas. Miralé (1998) descreve este tema como "o conjunto de elementos físico-químicos, ecossistemas naturais e sociais em que se insere o Homem, individual e socialmente, num processo de interação que atenda ao desenvolvimento das atividades humanas, à preservação dos recursos naturais e das características essenciais do entorno, dentro de padrões de qualidade definidos".

A lei Federal $n^{\circ} 6.938 / 81$, em seu I, do artigo $3^{\circ}$, que trata da Política Nacional do Meio Ambiente, define o mesmo como "o conjunto de condições, leis, influências e interações de ordem física, química e biológica, que permite, abriga e rege a vida em todas as suas formas". Dessa forma, tendemos a interpretar essa expressão de uma forma ampla, não se referindo apenas à natureza propriamente dita, mas sim a uma realidade complexa, resultante do conjunto de elementos físicos, químicos, biológicos e sócio-econômicos, bem como de suas inúmeras interações que ocorrem dentro de sistemas naturais, artificiais, sociais e culturais.

Assim como a expressão "meio ambiente", a palavra saúde é muito abrangente, não se referindo somente à ausência de doenças, mas sim a um completo bem-estar físico, mental e social de um indivíduo. Nesse sentido, o artigo $3^{\circ}$ da Lei $\mathrm{n}^{\mathrm{o}} 8.080 / 90$, consigna que "a saúde tem como fatores determinantes e condicionantes, entre outros, a alimentação, a moradia, o saneamento básico, o meio ambiente, o trabalho, a renda, a educação, o transporte, o lazer e o acesso aos bens e serviços essenciais". Esta definição deixa claro que o termo "saúde" 
engloba uma série condições que devem estar apropriadas para o bem estar completo do ser humano, incluindo o meio ambiente equilibrado.

O homem é parte integrante da natureza e, nesta condição, precisa do meio ambiente saudável para ter uma vida plena e saudável. Isso implica em que, qualquer dano causado ao meio ambiente provoca prejuízos à saúde pública e vice-versa. "A existência de um é a própria condição da existência do outro" (GRANZIERA e DALLARI, 2005), razão pela qual o ser humano deve realizar suas atividades respeitando e protegendo a natureza.

Inúmeras são as situações que demonstram a relação entre o meio ambiente e a saúde, tais como: Os efeitos nocivos à saúde pela utilização de água contaminada ou pela ingestão de alimentos contaminados. A inexistência de saneamento básico adequado, os maus hábitos de higiene, as condições precárias de vida de determinadas regiões do planeta são fatores que estão intimamente ligados com o meio ambiente e que contribuem para a transmissão da doença. Como afirma Machado (2002), "A água infectada, além de disseminar a doença ao ser ingerida, pode também contaminar peixes, mariscos, camarões etc..".

Também, o jornal "A Folha de S. Paulo" noticiou em outubro de 2004, que as enormes quantidades de substâncias químicas encontradas no ar, na água, nos alimentos e nos produtos utilizados rotineiramente estão diretamente relacionadas com uma maior incidência de câncer, de distúrbios neurocomportamentais, de depressão e de perda de memória. Tal reportagem também divulgou dados do Instituto Nacional do Câncer dos EUA, apontando que dois terços dos casos de câncer daquele país tem causas ambientais (GERHARDT, 2004). Este mesmo artigo ainda menciona uma pesquisa feita com cinqüenta controladores de trânsito da cidade de S. Paulo (conhecidos como "marronzinhos"), não fumantes e sem doenças prévias. A conclusão foi que todos apresentavam elevação da pressão arterial e variação da freqüência cardíaca nos dias de maior poluição atmosférica. Além disso, 33\% deles possuíam condições típicas de fumantes, como redução da capacidade pulmonar e inflamação freqüente dos brônquios.

Assim, observa-se, diariamente que é possível presenciar várias situações em que a degradação ambiental causa problemas na saúde e nas condições de vida do homem.

Em detrimento a essa situação, a legislação brasileira tenta amenizar a situação, como se pode observar no artigo 225, da Constituição Federal: "Todos têm direito ao meio ambiente ecologicamente equilibrado, bem de uso comum do povo e essencial à sadia qualidade de vida, impondo-se ao Poder Público e à coletividade o dever de defendê-lo e preservá-lo para as presentes e futuras gerações". Neste caso, observa-se que o dispositivo em foco é 
categórico ao afirmar que o meio ambiente ecologicamente equilibrado é essencial à sadia qualidade de vida, ou seja, à própria saúde.

O artigo 200 da mesma Lei também fixa algumas atribuições do Sistema Único de Saúde (SUS), dentre os quais se menciona a fiscalização de alimentos, bebidas e água para o consumo humano (inciso VI) e a colaboração na proteção do meio ambiente (inciso VIII).

Também a Lei Federal $\mathrm{n}^{\mathrm{o}}$ 6.938/81, conhecida como Política Nacional do Meio Ambiente, tem por objetivo a preservação, melhoria e recuperação da qualidade ambiental favorável à vida e, portanto, à saúde, visando assegurar condições ao desenvolvimento sócioeconômico e à proteção da dignidade humana (artigo $2^{\circ}$ ). Esta lei define poluição como a degradação da qualidade ambiental resultante das atividades que direta ou indiretamente prejudiquem a saúde, a segurança e o bem-estar da população (artigo $3^{\circ}$, inciso III, alínea "a").

Ainda cumpre mencionar a Lei $\mathrm{n}^{0} 8.080 / 90$, que regula em todo país as ações e serviços de saúde. Essa lei, além de consignar o meio ambiente como um dos vários fatores condicionantes para a saúde (artigo $3^{\circ}$ ), prevê uma série de ações integradas relacionadas à saúde, meio ambiente e saneamento básico.

Como visto, são diversos os instrumentos reguladores que nos mostram a indissociabilidade das questões ambientais e de saúde humana.

\section{Prevenindo o futuro ambiental}

O Direito Ambiental, que visa a manutenção de um perfeito equilíbrio nas relações do homem com o meio ambiente, possui alicerces próprios (princípios), que são decorrentes não apenas de um sistema normativo ambiental, mas também do sistema de direito positivo em vigor (MIRALÉ, 1998).

Dentre os diversos princípios do Direito Ambiental, cumpre destacar os princípios da prevenção e da precaução. O princípio da prevenção se caracteriza pela "prioridade que deve ser dada às medidas que evitem o nascimento de atentados ao ambiente, de molde a reduzir ou eliminar as causas de ações suscetíveis de alterar sua qualidade" (ANTUNES, 1999). Pelo princípio da prevenção, permite-se a instalação de uma determinada atividade ou empreendimento, impedindo, todavia, que ele cause danos futuros, por meio de medidas mitigadoras ou de caráter preventivo.

Antunes (1999) nos informa ainda haver "um dever jurídico-constitucional de levar em conta o meio ambiente quando se for implantar qualquer empreendimento econômico". 
Assim, segundo o referido autor, a constituição brasileira obriga todo empreendedor a proteger o meio ambiente ao exercer sua atividade econômica, razão pela qual se conclui que o princípio da prevenção impõe o equilíbrio entre o desenvolvimento sócio-econômico e a preservação ambiental.

O principio da precaução, por outro lado, "é um estágio além da prevenção, à medida que o primeiro (precaução) tende à não realização do empreendimento, se houver risco de dano irreversível, e o segundo (prevenção) busca, ao menos em um primeiro momento, a compatibilização entre a atividade e a proteção ambiental" (GRANZIERA e DALLARI, 2005). Assim, pelo princípio da precaução, quando existe risco ou incerteza científica de dano ambiental, a atividade sequer poderá ser licenciada.

Machado (2002), nos orienta que,

(...) a implementação do princípio da precaução não tem por finalidade imobilizar as atividades humanas. Não se trata da precaução que tudo impede ou que em tudo vê catástrofes ou males. O princípio da precaução visa à durabilidade da sadia qualidade de vida das gerações humanas e à continuidade da natureza existente no planeta.

E ainda que,

(...) a precaução caracteriza-se pela ação antecipada diante do risco ou do perigo. (...) No mundo da precaução há uma dupla fonte de incerteza: o perigo ele mesmo considerado e a ausência de conhecimentos científicos sobre o perigo. A precaução visa a gerir a espera da informação. Ela nasce da diferença temporal entre a necessidade imediata de ação e o momento onde nossos conhecimentos científicos vão modificar-se.

Um exemplo é o caso ocorrido em junho de 1999, onde o Juiz de Direito da $6^{\text {a }}$ Vara da Secção Judiciária do Distrito Federal, acolheu expressamente o princípio da precaução na ação judicial proposta pelo Instituto Brasileiro de Defesa do Consumidor contra a União Federal e a Monsanto do Brasil Ltda., ao proibir o plantio e comercialização de sementes da soja transgênica enquanto não fosse apresentado o Estudo Prévio de Impacto Ambiental e enquanto não fosse regulamentado, pelo Poder Público, as normas de biossegurança e de rotulagem de Organismos Geneticamente Modificados (MACHADO, 2002). 
Dessa forma, percebe-se que tais princípios visam restringir e até mesmo proibir a implantação de novos empreendimentos, na hipótese dos mesmos oferecerem risco ao ambiente e a saúde das pessoas. Afinal, o Direito Ambiental possui caráter preventivo, pois é praticamente impossível a reparação integral nos casos de degradação ambiental, já que na maioria das vezes a região afetada jamais voltará ao estado em que se encontrava antes do evento danoso. "Muitos danos ambientais são compensáveis, mas, sob a ótica da ciência e da técnica, irreparáveis" (MIRALÉ, 1998). E, da mesma forma, são várias as doenças causadas por danos ambientais cujas seqüelas se tornam irreversíveis para o homem.

Milaré apud FELDMANN (1998), menciona que,

Não podem a humanidade e o próprio Direito contentar-se em reparar e reprimir o dano ambiental. (...). Como reparar o desaparecimento de uma espécie ? Como trazer de volta uma floresta de séculos que sucumbiu sob a violência do corte raso ? Como purificar um lençol freático contaminado por agrotóxicos?.

Por isso, o legislador constituinte atribuiu ao Poder Público o dever de aplicar os princípios da prevenção e precaução, por meio do controle da produção, comercialização e do emprego de técnicas, métodos e substâncias que comportem risco para a qualidade de vida e para o meio ambiente. Observe-se o artigo 225, parágrafo primeiro, inciso V, da Constituição Federal.

O poder de polícia, o zoneamento ambiental, as normas legais, os padrões ambientais, a aplicação de penalidades, o licenciamento ambiental, o estudo prévio de impacto ambiental, as regras de construção, o controle da poluição, o saneamento básico, o controle do uso do solo nos meios urbanos e rurais, o planejamento do crescimento da cidade e outros, são exemplos de instrumentos de controle ambiental onde se costuma aplicar os princípios da prevenção e da precaução. Lamentavelmente, os princípios citados neste estudo não estão sendo empregados na forma preconizada pelo legislador constitucional, o que vem colaborando com o aumento dos problemas ambientais e com o agravamento das condições de vida e de saúde o homem. 


\section{Considerações finais}

O ordenamento jurídico brasileiro parece bastante claro, em suas várias normas, sobre a indissociabilidade dos temas concernentes à saúde e ao meio ambiente. A atuação dos princípios da prevenção e da precaução são de suma importância, pois eles restringem e até mesmo proíbem o estabelecimento de um empreendimento que potencialmente ofereça riscos à natureza e à saúde da população.

Sob um aspecto geral, considera-se que o direito brasileiro fornece as ferramentas necessárias para que o Poder Público possa aplicar os princípios da prevenção e precaução na preservação dos recursos naturais. Entretanto, observa-se que, alguns mecanismos legais destinados à proteção do meio ambiente e, conseqüentemente, da saúde humana, esvaem-se no ar, atingidos por males maiores, capitaneados pela corrupção, que, por sua vez, é alimentada pela ambição e pela ignorância dos homens.

Dessa forma, não basta a existência material da lei, pois embora as leis ambientais em nosso país sejam avançadas, nota-se ainda uma lacuna, consistente na articulação institucional.

São vários os motivos pelos quais a legislação e os princípios ambientais têm aplicabilidade limitada, valendo destacar: (a) dissociação entre os objetivos das políticas ambientais e as estratégias de desenvolvimento econômico adotadas pelo próprio Poder Público; (b) presença de interesses sociais contraditórios segundo cada instância de governo; (c) falta de recursos financeiros para a área ambiental; (d) falta de capacitação técnica dos órgãos ambientais, entre outros.

Assim, torna-se urgente superar as barreiras que obstruem os processos de implementação das normas legais de cunho ambiental, sob pena da ineficiência dos princípios constitucionais estabelecidos na Carta de 1988, dentre eles os princípios da prevenção e da precaução.

É preciso também que as políticas relacionadas à saúde pública e ao meio ambiente caminhem em conjunto e, que os órgãos dos três níveis de governo ligados a essas áreas, bem como aos setores de agricultura e trabalho, não atuem isoladamente. Afinal, as conseqüências dos problemas ambientais que afetam a saúde da população não respeitam fronteiras geográficas ou níveis de competência.

Em termos de saúde humana e meio ambiente, não basta indenizar os impactos negativos causados ou a dor e as irreparáveis seqüelas causadas pelas doenças surgidas por conta da degradação da natureza. É preciso agir antes, empregando de forma efetiva o 
princípio da prevenção e, ser for preciso, o da precaução. Afinal, preservar e conservar o meio ambiente se traduz na garantia de sobrevivência da própria espécie humana e, nesse sentido, Souza (2004) é claro: "a natureza não pode se adequar às leis criadas pelo homem, muito pelo contrário, o direito deve ser formulado em respeito às limitações naturais, submetendo às atividades econômicas às exigências naturais".

\section{Referências}

ANTUNES, Paulo de Bessa, Direito Ambiental. $3^{\text {a }}$ ed. Rio de Janeiro: Lumen Juris, 1999.

CASTELlANI, Beatriz R.; SILVEIRA Ghisleine Trigo; GALVÃO, Heloisa A.; GARDENAL Marlene. O Trabalho educacional na prevenção da cólera, Volume 2, Secretaria de Estado e Educação SP, São Paulo, 1994

FUNDAÇÃO ESTADUAL DE ENGENHARIA DO MEIO AMBIENTE (Rio de Janeiro RJ), Vocabulário Básico de Meio Ambiente, Rio de Janeiro, 1990, p. 133/135.

GRANZIERA, Maria Luiza Machado; DALLARI, Sueli Gandolfi. Direito Sanitário e Meio Ambiente. In: PHILIPPI JR., Arlindo: ALVES, Alaor Caffé (Editores). Curso Interdisciplinar de Direito Ambiental, Barueri-SP: Manole, 2005. p. 607/643.

GERHARDT, Rodrigo. O meio ambiente contra ataca. A Folha de S. Paulo, S. Paulo, caderno Folha Equilíbrio, 28 de outubro de 2004.

HOGAN, Daniel Joseph. Crescimento Populacional e Desenvolvimento Sustentável. São Paulo 2002.

MACHADO, Paulo Affonso de Leme, Direito Ambiental Brasileiro. 10 $0^{\mathrm{a}}$ ed. São Paulo: Malheiros Editores, 2002, MIRALÉ, Edis. Direito do Ambiente, Editora RT. . 'Princípios Fundamentais do Direito do Ambiente'. Revista dos Tribunais, São Paulo: Editora Revista dos Tribunais, outubro de 1998, $\mathrm{n}^{\circ} 756$.

MIRRA, Alvaro Luiz Valery, Princípios Fundamentais do direito ambiental, Revista de Direito Ambiental n 2, São Paulo, 1996, RT.

MORAES, Márcia Elayne Berbich, A (In) Eficiência do Direito Penal Moderno para a Tutela do Meio Ambiente (Lei no 9.605/98), Rio de Janeiro 2004, Editora Lumen Juris. SILVA, José Afonso da, Direito Ambiental Constitucional. $4^{\text {a }}$ ed. São Paulo: Malheiros Editores, 2002. 
SOUZA, Paulo Roberto Pereira de. A servidão Ambiental Florestal como Instrumento de Proteção Continental do Meio Ambiente. Disponível em <www.oab.org.br/comissões/coda/files/artigos \{05449877-7D8B-4134-A3D5DBE9A3BB8C99\}_servidaoambiental.pdf $>$ Acesso em: 28 mai. 2004.

\section{Sobre os autores:}

(1) Hidemburgo Gonçalves Rocha é Mestre em Bioquímica e Professor Adjunto da Universidade Regional do Cariri e da Universidade Federal do Ceará, atuando na Faculdade de Medicina do Cariri. E_mail: hidemburgo.rocha@bol.com.br.

(2) Lindeberg Rocha Freitas é Doutor em Ciências e Tecnologia dos alimentos. 